\title{
Coenzyme $Q$ releases the inhibitory effect of free fatty acids on mitochondrial glycerophosphate dehydrogenase
}

\author{
Hana Rauchová ${ }^{1}$, Zdeněk Drahota ${ }^{2, \bowtie}$, Pavel Rauch ${ }^{3}$, Romana Fato ${ }^{4}$ and \\ Giorgio Lenaz ${ }^{4}$ \\ ${ }^{1}$ Center for Experimental Cardiovascular Research and ${ }^{2}$ Center for Molecular Genomics of the \\ Institute of Physiology, Czech Academy of Sciences, Prague, Czech Republic, ${ }^{3}$ Department of \\ Biochemistry and Microbiology, Instiute Chem. Technology Prague, Czech Republic; \\ ${ }^{4}$ Department of Biochemistry, Medical School, University of Bologna, Bologna, Italy
}

Received: 27 May 2003; accepted: 6 June 2003

Key words: mitochondrial glycerophosphate dehydrogenase, free fatty acids, coenzyme Q, brown adipose tissue

\begin{abstract}
Data presented in this paper show that the size of the endogenous coenzyme Q (CoQ) pool is not a limiting factor in the activation of mitochondrial glycerophosphate-dependent respiration by exogenous $\mathrm{CoQ}_{3}$, since successive additions of succinate and NADH to brown adipose tissue mitochondria further increase the rate of oxygen uptake. Because the inhibition of glycerophosphate-dependent respiration by oleate was eliminated by added $\mathrm{CoQ}_{3}$, our data indicate that the activating effect of $\mathrm{CoQ}_{3}$ is related to the release of the inhibitory effect of endogenous free fatty acids (FFA). Both the inhibitory effect of FFA and the activating effect of $\mathrm{CoQ}_{3}$ could be demonstrated only for glycerophosphate-dependent respiration, while succinate- or NADH-dependent respiration was not affected. The presented data suggest differences between mitochondrial glycerophosphate dehydrogenase and succinate or NADH dehydrogenases in the transfer of reducing equivalents to the CoQ pool.
\end{abstract}

Mitochondrial glycerophosphate dehydrogenase (mGPDH), together with cytosolic glycerophosphate dehydrogenase (cGPDH), form the glycerophosphate shuttle (Estabrook
\& Sacktor, 1958; Bucher \& Klingenberg, 1958). This shuttle is involved, alongside with the malate-aspartate shuttle (Scholz et al., 2000), in the reoxidation of cytosolic NADH, bypass-

\footnotetext{
Experimental work was supported by grants: COST 918.50, GAČR 303/03/0799, AVOZ5011922 and by a Joint Project in the framework of Czech-Italian scientific and technological co-operation No. 43/BI4.

${ }^{\square}$ Correspondence and requests for reprints should be addressed to: Dr. Zdeněk Drahota, Institute of Physiology, Czech Academy of Sciences of the Czech Republic, 14220 Prague 4, Vídeňská 1083, Czech Republic; phone: (420) 241062 432; e-mail: drahota@biomed.cas.cz

Abbreviations: BSA, bovine serum albumin; cGPDH, cytosolic glycerophosphate dehydrogenase; CoQ, coenzyme $\mathrm{Q} ; \mathrm{CoQ}_{3}$, short-chain homolog of $\mathrm{CoQ}$; mGPDH, mitochondrial glycerophospahte dehydrogenase.
} 
ing complex I. In contrast with the malateaspartate shuttle, the glycerophosphate shuttle is highly active only in insect flight muscle cells (Estabrook \& Sactor, 1958; Bolter \& Chefurka, 1990) and in brown adipose tissue of newborn mammals and in hibernating mammals (Houštěk et al., 1975). However, some publications showed an important role of this shuttle also in other mammalian organs, such as placenta (Olivera \& Meigs, 1975; Swierczynski et al., 1976), testes (MacDonald \& Brown, 1996) or pancreatic $\beta$-cells (Ishihara et al., 1996) and in the regulation of various physiological and pathological processes, such as thermogenesis (Lardy et al., 1995), diabetes (Senner et al., 1993) or obesity (Lardy et al., 1989). Brown et al. (2002) demonstrated a lethal effect of elimination of the two genes for mGPDH and cGPDH in mice.

In spite of this increasing interest, there are still many problems not fully clarified, related to the complex system of factors regulating $\mathrm{mGPDH}$ expression in various organs and its participation in the regulation of the cell energy provision system.

In a previous study we found that activity of mGPDH is highly stimulated by $\mathrm{CoQ}_{3}$, a shortchain homolog of coenzyme Q (Rauchová et al., 1992). The aim of the present study was to further clarify the mechanism of the $\mathrm{CoQ}_{3}$ activating effect on mGPDH. Because in brown adipose tissue mitochondria, mGPDH is highly stimulated by removal of endogenous free fatty acids (FFA) (Houštěk \& Drahota, 1975; Rauchová \& Drahota, 1984), we tested whether activation of $\mathrm{mGPDH}$ is related to the limited pool size of endogenous CoQ as the acceptor of reducing equivalents from the highly active $\mathrm{mGPDH}$, or whether this activation indicates that $\mathrm{CoQ}_{3}$ can compete with the endogenous FFA and release their inhibitory effect.

\section{MATERIALS AND METHODS}

Brown adipose tissue of adult, male Syrian hamsters adapted at $4^{\circ} \mathrm{C}$ for 3 weeks was used.
Mitochondria were isolated in $0.25 \mathrm{M}$ sucrose, $10 \mathrm{mM}$ Tris/HCl, $1 \mathrm{mM}$ EDTA, $\mathrm{pH} 7.4$ as described by Hittelman et al. (1969) and stored at $-70^{\circ} \mathrm{C}$. Enzyme activities and respiration were measured using fresh or frozen-thawed mitochondria.

Glycerophosphate and succinate cytochrome $c$ reductases activities were determined by measuring the rate of cytochrome $c$ reduction at $550 \mathrm{~nm}$ in a medium containing $50 \mathrm{mM}$ $\mathrm{KCl}, 20 \mathrm{mM}$ Tris/ $\mathrm{HCl}, 1 \mathrm{mM}$ EDTA, $2 \mathrm{mM}$ $\mathrm{KCN}, 100 \mu \mathrm{M}$ cytochrome $c$ and $50-75 \mu \mathrm{g}$ mitochondrial protein $/ \mathrm{ml}, \mathrm{pH}$ 7.4. The reaction was started by addition of $25 \mathrm{mM}$ glycerophosphate. The enzyme activity was expressed as nmol cytochrome $c$ reduced per min per mg protein using an extinction coefficient of 19.1. The activity of glycerophosphate and succinate dehydrogenase was determined using dichlorophenol indophenol (DCIP) as an artificial electron acceptor as described previously (Rauchová et al., 1993).

Oxygen consumption was measured with a High Resolution Oxygraph (OROBOROS, Austria) in a medium containing $100 \mathrm{mM} \mathrm{KCl,} 20$ $\mathrm{mM}$ Tris $/ \mathrm{HCl}, 4 \mathrm{mM}$ K-phosphate, $3 \mathrm{mM}$ $\mathrm{MgCl}_{2}, 1 \mathrm{mM}$ EDTA at $\mathrm{pH}$ 7.2. The oxygraphic curves presented are the first derivative of oxygen tension changes. For calculation and presentation of oxygraphic data OROBOROS software was used (Gnaiger et al., 1995). Oxygen consumption is expressed as pmol or nmol $\mathrm{O}_{2}$ per second per mg protein. Proteins were determined according to Lowry et al. (1951) using bovine serum albumin as a standard.

\section{RESULTS}

In this study we extend our previous findings (Rauchová et al., 1992) that the activating effect of $\mathrm{CoQ}_{3}$ is specific for glycerophosphate cytochrome $c$ reductase and cannot be detected when succinate cytochrome $c$ reductase activity is measured. Data in Table 1 demonstrate the antimycin-sensitive and insensitive portion of the glycerophosphate and succinate 
Table 1. Activation of glycerophosphate and succinate cytochrome $c$ reductase activity of brown adipose tissue mitochondria by $\mathrm{CoQ}_{3}$ and menadione

\begin{tabular}{|c|c|c|c|}
\hline & \multicolumn{3}{|c|}{ Enzyme activity (nmol/min per mg protein) } \\
\hline & Control & $+\mathrm{CoQ}_{3}(20 \mu \mathrm{M})$ & + Menadione $(800 \mu \mathrm{M})$ \\
\hline \multicolumn{4}{|c|}{ Glycerophosphate cytochrome $c$ reductase } \\
\hline Total activity & $422.9 \pm 31(100 \%)$ & $781.2 \pm 23(100 \%)$ & $718.9 \pm 5 \quad(100 \%)$ \\
\hline AA-sensitive & $392.7 \pm 31 \quad(93 \%)$ & $700.3 \pm 15 \quad(90 \%)$ & $123.0 \pm 64(10 \%)$ \\
\hline AA-insensitive & $30.2 \pm 4 \quad(7 \%)$ & $80.8 \pm 30(10 \%)$ & $643.4 \pm 68 \quad(90 \%)$ \\
\hline \multicolumn{4}{|c|}{ Succinate cytochrome $c$ reductase } \\
\hline Total activity & $265.4 \pm 33(100 \%)$ & $250.0 \pm 15(100 \%)$ & $196.3 \pm 39$ (100\%) \\
\hline AA-sensitive & $251.1 \pm 34(93 \%)$ & $185.2 \pm 11(74 \%)$ & $85.9 \pm 22 \quad(44 \%)$ \\
\hline AA-insensitive & $17.7 \pm 2 \quad(7 \%)$ & $65.9 \pm 4 \quad(44 \%)$ & $110.4 \pm 18(56 \%)$ \\
\hline
\end{tabular}

Experimental conditions were the same as in Fig 1 . Glycerophosphate was $25 \mathrm{mM}$, succinate $25 \mathrm{mM}$, antimycin A $1 \mu \mathrm{M}$. Data presented are means of four experiments \pm S.E.M.

cytochrome $c$ reductase activities and compare the activating effect of $\mathrm{CoQ}_{3}$ with that of menadione. We found that both reductases were inhibited by $93 \%$ by antimycin A. The inhibitory effect of antimycin A on glycerophosphate cytochrome $c$ reductase was nearly completely restored by menadione, but succinate cytochrome $c$ reductase activity was restored by the same menadione concentration only by $50 \%$. Because, in contrast to nected with a modification of the mGPDH function.

In further experiments we compared the rates of cytochrome $c$ reductase activity in the presence of glycerophosphate and/or succinate. As demonstrated in Fig. 1, the rate of cytochrome $c$ reduction is significantly higher when both substrates are present in the medium. Similar data were also obtained by polarographic measurements. The rate of oxy-
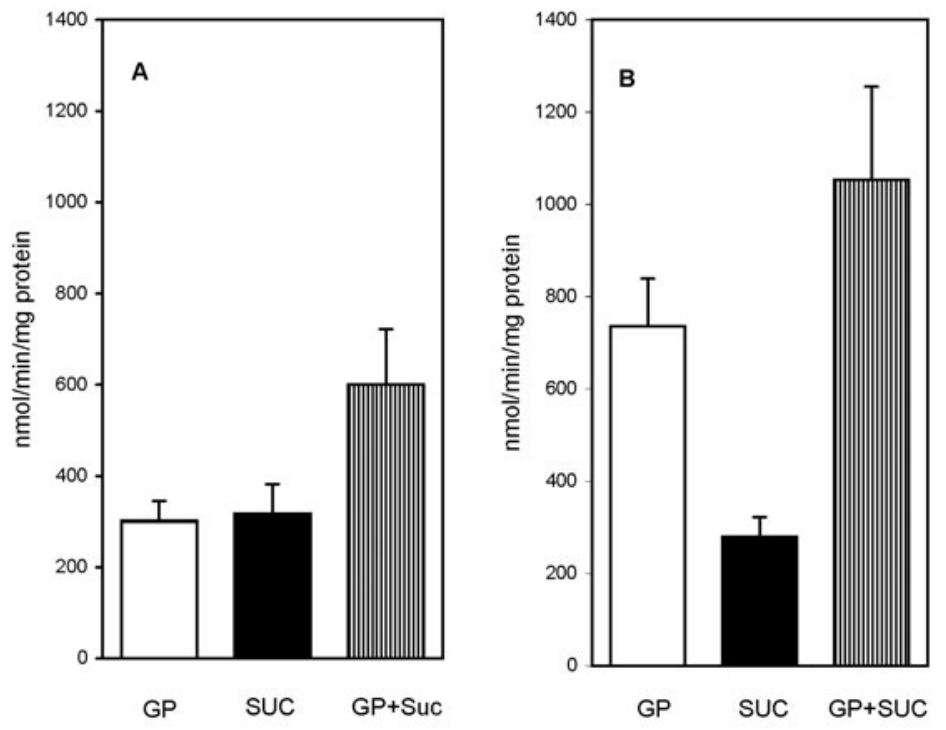

Figure 1. Glycerophosphate and succinate cytochrome $c$ reductase activities (nmol/min per $\mathrm{mg}$ protein) of brown adipose tissue mitochondria.

Where indicated, glycerophosphate (GP) was $25 \mathrm{mM}$ and succinate (SUC) $25 \mathrm{mM}$ or both substrates were present. Activities were determined in the absence (A) and in the presence (B) of $0.2 \%$ fatty acid free bovine serum albumin. Frozen-thawed mitochondria were used. Data presented are means of four experiments \pm S.E.M.

menadione, $\mathrm{CoQ}_{3}$ added in the presence of antimycin A cannot shuttle electrons from glycerophosphate dehydrogenase to cytochrome $c$, its activating effect must be con- gen uptake in the presence of glycerophosphate was further increased by subsequent additions of succinate and NADH (Fig. 2, Table 2). All these data clearly indi- 
cate that the endogenous CoQ pool cannot be the limiting factor for the rate of $\mathrm{mGPDH}$ activity and that the activating effect of $\mathrm{CoQ}_{3}$ must be due to modification of mGPDH activity.

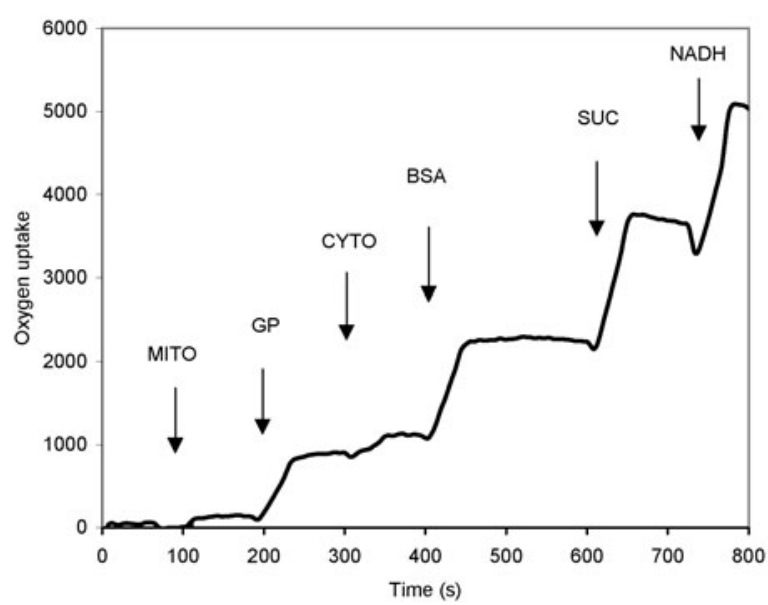

Figure 2. Oxygen consumption by brown adipose tissue mitochondria in the presence of various respiratory substrates.

To the incubation medium containing $100 \mathrm{mM} \mathrm{KCl}, 10$ $\mathrm{mM}$ Tris/HCl, $4 \mathrm{mM}$ K-phosphate, $3 \mathrm{mM} \mathrm{MgCl}_{2}, 1 \mathrm{mM}$ EDTA ( $\mathrm{pH}$ 7.2), frozen-thawed brown adipose tissue mitochondria (MITO), $0.1 \mathrm{mg}$ protein/ml of medium, 10 $\mathrm{mM}$ glycerophosphate (GP), $25 \mu \mathrm{M}$ cytochrome $c$ (CYTO), $0.4 \%$ bovine serum albumin (BSA), $10 \mathrm{mM}$ succinate (SUC) and $0.2 \mathrm{mM} \mathrm{NADH}$ were added as indicated. The oxygraphic curve is the first derivative of oxygen concentration changes. Oxygen uptake is expressed as pmol oxygen per second per mg protein. The same results were obtained using three preparations of mitochondria.

In our previous papers we found that the mGPDH activity is inhibited by endogenous FFA and that the inhibitory effect of endogenous fatty acids can be released by fatty acid oxidation (Bulychev et al., 1972) or by their extraction by added bovine serum albumin (BSA) (Houštěk \& Drahota, 1975; Rauchová \& Drahota, 1984). Data presented in Fig. 3 demonstrate that BSA and oleate induced pronounced changes of glycerophosphate cytochrome $c$ oxidoreductase activity. Both BSA and oleate had a less pronounced effect on the activity of glycerophosphate dichlorophenol indophenol oxidoreductase. These data are thus in agreement with our previous proposal that free fatty acids inhibit the transfer of reducing equivalents from glycerophosphate dehydrogenase to the CoQ pool (Rauchová \& Drahota, 1984).

In further experiments we tested to what extent $\mathrm{CoQ}_{3}$ can modify the inhibition of mGPDH by added oleate and we found that $\mathrm{CoQ}_{3}$ can fully restore glycerophosphate-de-

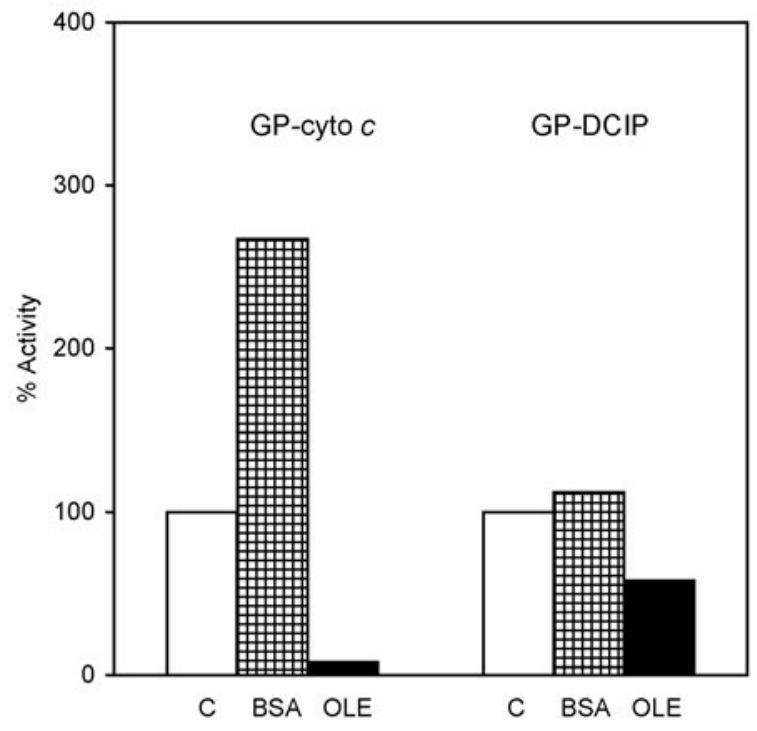

Figure 3. The effect of bovine serum albumin and Na-oleate on glycerophosphate cytochrome $c$ oxidoreductase (GP-cyto $c$ ) and glycerophosphate dichlorophenol indophenol oxidoreductase (GP-DCIP).

Bovine serum albumin (BSA) was $0.2 \%$ and Na-oleate (OLE) was $15 \mu \mathrm{M}$. C indicates control samples. Frozenthawed mitochondria were used. The same results were obtained using three preparations of mitochondria.

pendent respiration inhibited by oleate (Fig. 4, Table 3). However, the activating effect of $\mathrm{CoQ}_{3}$ was less efficient than that of bovine serum albumin. Added $\mathrm{CoQ}_{3}$ compensated only the inhibition caused by added oleate and even higher concentrations of added $\mathrm{CoQ}_{3}$ were not able to increase the oxygen uptake to values obtained after addition of BSA. Also the activating effect of BSA on 
Table 2. Respiration of brown adipose tissue mitochondria in the presence of various substrates

\begin{tabular}{|c|c|c|}
\hline Additions & \multicolumn{2}{|c|}{ nmol oxygen per second per mg protein } \\
\hline Glycerophosphate (10 mM) & 0.97 & $39 \%$ \\
\hline $\mathrm{GP}+\operatorname{cyt} c(25 \mu \mathrm{M})$ & 1.22 & $49 \%$ \\
\hline $\mathrm{GP}+\operatorname{cyt} c+\mathrm{BSA}(0.1 \%)$ & 2.48 & $100 \%$ \\
\hline+ Succinate $(10 \mathrm{mM})$ & 4.08 & $164 \%$ \\
\hline$+\mathrm{NADH} \quad(0.2 \mathrm{mM})$ & 5.51 & $228 \%$ \\
\hline
\end{tabular}

Experimental conditions are the same as described in Fig. 2. Similar results were obtained in three experiments with mitochondria isolated from four hamsters.

Table 3. Release of the oleate-induced inhibition of mGPDH by $\mathrm{CoQ}_{3}$.

\begin{tabular}{llll}
\hline \multirow{2}{*}{ Additions } & \multicolumn{2}{l}{$\begin{array}{l}\text { Oxygen uptake } \\
\text { (nmol per second per mg protein) }\end{array}$} & \\
\cline { 2 - 4 } & \multicolumn{2}{l}{ Without cytochrome $c$} & With cytochrome $c(25 \mu \mathrm{M})$ \\
\hline $10 \mathrm{mM}$ glycerophosphate & $1.37 \quad(100 \%)$ & 1.36 & $(100 \%)$ \\
+ Na-oleate $(15 \mu \mathrm{M})$ & $0.51 \quad(37 \%)$ & 0.40 & $(29 \%)$ \\
$+\mathrm{CoQ}_{3}(50 \mu \mathrm{M})$ & $1.05 \quad(77 \%)$ & 1.30 & $(96 \%)$ \\
$+\mathrm{BSA}(0.1 \%)$ & $2.15 \quad(169 \%)$ & 3.76 & $(276 \%)$ \\
\hline
\end{tabular}

Experimental conditions were the same as described in Fig 3. Similar results were obtained in three experiments with mitochondria isolated from four hamsters.

glycerophosphate-dependent respiration was higher than that of $\mathrm{CoQ}_{3}$ (Fig. 5) and $\mathrm{CoQ}_{3}$ could not further activate glycerophosphate-dependent oxygen consumption in the presence of BSA (Table 4).

\section{DISCUSSION}

Activity of mGPDH is regulated by many factors, such as calcium ions (MacDonald \& Brown, 1996), acyl CoA esters (Bukowiecki \& Lindberg, 1974), free fatty acids (Drahota \& Houštěk, 1976; Rauchová \& Drahota, 1984; Rauchová et al. 1993) or intermediates of glycolysis (Swierczynski et al., 1977). Its biogenesis is under the control of thyroid and steroid hormones (Weitzel et al., 2001).

Regulation by FFA is of particular importance because the inhibitory effect of FFA is completely reversible. When fatty acids bound to isolated mitochondria are oxidized (Bulychev et al., 1972) or removed by BSA treatment (Drahota \& Houštěk, 1976; Rauchová \& Drahota, 1984) the inhibitory effect disappears. The mechanism of this inhibitory effect has not yet been fully clarified. It seems that FFA do not interact directly with the catalytic site of the enzyme as do acyl-CoA esters (Bukowiecki \& Lindberg, 1974), but modify the transfer of reducing equivalents to coenzyme Q or to artificial acceptors.

The inhibitory effect of FFA is specific for glycerophosphate oxidase or cytochrome $c$ reductase activity. Succinate oxidase or cytochrome $c$ reductase activity is not inhibited by FFA nor activated by BSA (Houštěk \& Drahota, 1976). This supports our previous finding that the transfer of reducing equivalents from $\mathrm{mGPDH}$ to the coenzyme $\mathrm{Q}$ pool has a different mechanism than that from succinate and NADH dehydrogenases, most 

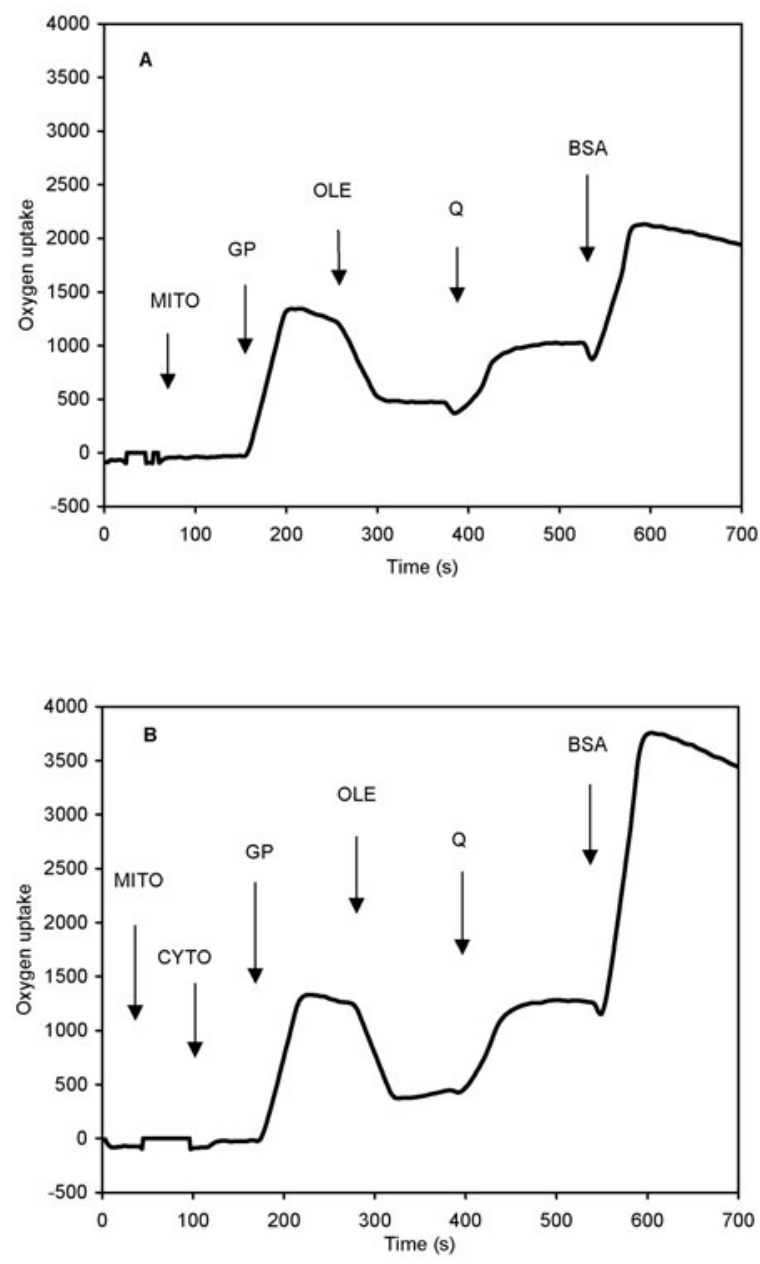

Figure 4. Inhibition by oleate of glycerophosphate-dependent oxygen consumption and the release of the inhibition by $\mathrm{CoQ}_{3}$ in the absence (A) and in the presence (B) of cytochrome $c$.

Where indicated, freshly isolated mitochondria (MITO) $0.1 \mathrm{mg}$ protein $/ \mathrm{ml}$, cytochrome $c$ (CYTO) $25 \mu \mathrm{M}$, glycerophosphate (GP) $10 \mathrm{mM}$, Na-oleate (OLE) $15 \mu \mathrm{M}$, coenzyme $\mathrm{Q}_{3}(\mathrm{Q}) 20 \mu \mathrm{M}$ and bovine serum albumin $0.2 \%$ (BSA) were added. The oxygraphic curves are the first derivatives of oxygen tension changes. Oxygen uptake is expressed as pmol oxygen per second per mg protein. The same results were obtained using three preparations of mitochondria.

probably due to the absence of a CoQ-binding protein in the $\mathrm{mGHPH}$ enzyme complex (Cottingham \& Ragan 1980a; 1980b; Rauchová et al.,1992; 1997).

Modulation of mGPDH activity by FFA may, however, occur also through their effect on membrane fluidity. As we found in previous studies, mGPDH activity correlates with membrane fluidity changes induced by FFA, both in the intact mitochondrial membrane (Amler et al., 1986) and in liposomes with incorporated mGPDH (Amler et al., 1990). In insect thoracic muscle mitochondria Wojtczak \& Nalecz (1979) found that the activity of mGPDH was dependent on the surface charge of the mitochondrial membrane and in liposomes it was dependent on their phospholipid composition (Nalecz et al., 1980).

As demonstrated in Fig. 4, $\mathrm{CoQ}_{3}$ can release the inhibition by added FFA. However, in these experimental conditions, $\mathrm{CoQ}_{3}$ increased mGPDH activity only to the level obtained before the addition of oleate. This could be related to the fact that, although the activating effect of both $\mathrm{CoQ}_{3}$ and BSA is related to fatty acid inhibition of mGPDH, evidently the mechanism of action of both substances is different. BSA is a more powerful activating agent because it can extract fatty acids from their binding sites whereas $\mathrm{CoQ}_{3}$ activation could be explained by competition with fatty acids for the fatty acid binding sites.

Data presented in this communication describe another mechanism which participates in the regulation of mitochondrial glycerophosphate dehydrogenase, viz. competition of CoQ and FFA, and support the idea that CoQ, besides its role in the transport of reducing equivalents and antioxidative protection (Lenaz, 2001), has an important role also in the regulation of cell metabolic processes as, e.g., in the regulation of uncoupling proteins function (Echtay et al., 2000; 2001).

The existence of a competition between FFA and $\mathrm{CoQ}_{3}$ at the acceptor site of $\mathrm{mGPDH}$ also suggests that the inhibitory effect of FFA is exerted by occupying the CoQ-reducing site in the enzyme, thus preventing transfer of reducing equivalents to the CoQ pool.

Recent models of organization of the mitochondrial respiratory chain suggest the existence of specific supramolecular aggregates formed by complexes III and IV or complexes 
Table 4. $\mathrm{CoQ}_{3}$ does not activate glycerophosphate oxidation in the presence of BSA

\begin{tabular}{lll}
\hline Additions & \multicolumn{2}{l}{$\begin{array}{l}\text { Oxygen uptake } \\
\text { (nmol per second per mg protein) }\end{array}$} \\
\hline $10 \mathrm{mM}$ glycerophosphate $+25 \mu \mathrm{M}$ cyt $c$ & $1.45 \quad(100 \%)$ \\
$10 \mathrm{mM}$ glycerophosphate $+25 \mu \mathrm{M}$ cyt $c+0.1 \% \mathrm{BSA}$ & $3.90 \quad(269 \%)$ \\
$10 \mathrm{mM}$ glycerophosphate $+25 \mu \mathrm{M}$ cyt $c+0.1 \% \mathrm{BSA}+50 \mu \mathrm{M} \mathrm{CoQ} 3$ & $3.32 \quad(229 \%)$ \\
\hline
\end{tabular}

Experimental conditions are the same as described in Fig. 3. Similar results were obtained in three experiments with mitochondria isolated from four hamsters.
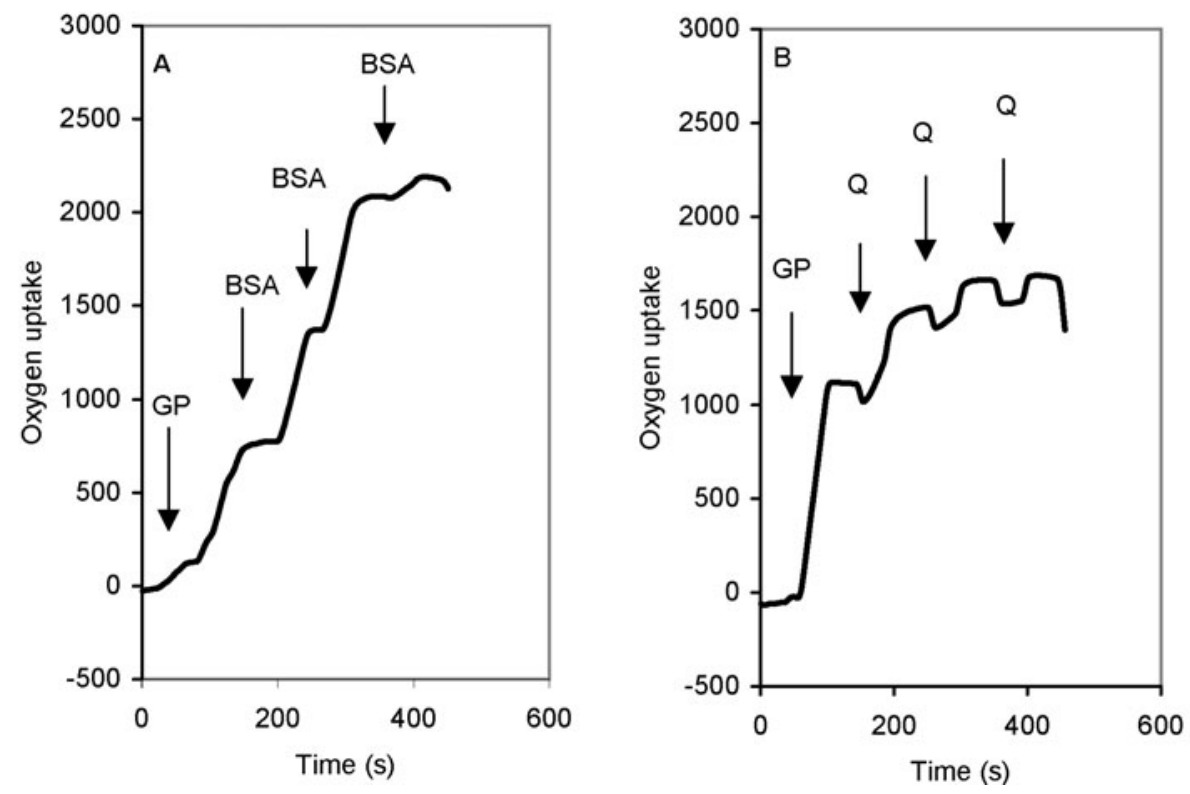

Figure 5. Activation of glycerophosphate-dependent respiration by BSA and CoQ.

Experimental conditions were the same as in Fig. 4. Where indicated glycerophosphate (GP) 10 mM, bovine serum albumin $0.2 \%$ (BSA) or coenzyme $\mathrm{Q}_{3}(\mathrm{Q}) 10 \mu \mathrm{M}$ were added.

I, III and IV (Schagger \& Pfeiffer, 2001). Succinate dehydrogenase is not involved. On the other hand, the state of mGPDH is not known although the lack of CoQ binding proteins (Cottingham \& Ragan, 1980a; 1980b) is in favour of electron transfer from the enzyme to the CoQ pool. Moreover, a previous study (Rauchová et al., 1997) has demonstrated a CoQ pool function for mGPDH. Thus, the transfer of reducing equivalents from succinate dehydrogenase and evidently also from glycerophosphate dehydrogenase must occur through the $\mathrm{CoQ}$ pool without direct interactions between individual complexes. The differences that exist between succinate and glycerophosphate dehydrogenases described in this communication and in a previous paper (Drahota et al., 2002) support our hypothesis that the transfer of reducing equivalents from succinate dehydrogenase is better protected against electron leak than that from glycerophosphate dehydrogenase.

\section{R E F E R E N C E S}

Amler E, Rauchová H, Svobodová J, Drahota Z. (1986) Regulation of glycerol-3-phosphate oxidation in mitochondria by changes in membrane viscosity. FEBS Lett.; 206: 1-3.

Amler E, Jasinská R, Drahota Z, Zborowski J. (1990) Membrane lateral pressure as a modu- 
lator of glycerol-3-phosphate dehydrogenase. FEBS Lett.; 271: 165-8.

Bolter CJ, Chefurka W. (1990) Extramitochondrial release of hydrogen peroxide from insect and mouse liver mitochondria using the respiratory inhibitors phosphine, myxothiazol, and antimycin and spectral analysis of inhibited cytochromes. Arch Biochem Biophys.; 278: 65-72.

Brown LJ, Koza RA, Marshall L, Kozak LP, Mac Donad MJ. (2002) Lethal hypoglycemic ketosis and glyceroluria in mice lacking both the mitochondrial and the cytosolic glycerol phosphate dehydrogenase. J Biol Chem.; 277: 32899-904.

Bucher T, Klingenberg M. (1958) Wege des Wasserstoffs in der lebendigen Organisation. Angew Chem.; 70: 552-70.

Bukowiecki LJ, Lindberg O. (1974) Control of sn-glycerol 3-phosphate dehydrogenase in brown adipose tissue mitochondria by calcium and acyl-CoA. Biochim Biophys Acta.; 348: 115-25.

Bulychev A, Kramer R, Drahota Z, Lindberg O. (1972) Role of a specific endogenous fatty acid fraction on the coupling-uncoupling mechanism of oxidative phosphorylation of brown adipose tissue. Exp Cell Res.; 72: 169-87.

Cottingham IR, Ragan CI. (1980a) Purification and properties of L-3-glycerophosphate dehydrogenase from pig brain mitochondria. Biochem J.; 192: 9-18.

Cottingham IR, Ragan CI. (1980b) The reconstitution of L-3-glycerophosphate cytochrome c oxidoreductase from L-3-glycerophosphate dehydrogenase ubiquinone-10 and ubiquinol cytochrom $c$ oxidoreductase. Biochem J.; 192: $19-31$.

Drahota Z, Chowdhury SKR, Floryk D, Mráček T, Wilhelm J, Rauchová H, Lenaz G, Houštěk J. (2002) Glycerophosphate-dependent hydrogen peroxide production by brown adipose tissue mitochondria and its activation by ferricyanide. J Bioenerg Biomembr:; 34: 105-13.
Echtay KS, Winkler E, Frischmuth K, Klingenberg M. (2000) Coenzyme Q is an obligatory factor for uncoupling protein function. Nature.; 408: 609-13.

Echtay KS, Winkler E, Frischmuth K, Klingenberg M. (2001) Uncoupling proteins 2 and 3 are highly active $\mathrm{H}^{+}$transporters and highly nucleotide sensitive when activated by coenzyme Q (ubiquinone). Proc Natl Acad Sci $U S$ A.; 98: 1416-21.

Estabrook RW, Sacktor B. (1958) Glycerophosphate oxidase in flight muscle mitochondria. J Biol Chem.; 233: 1014-19.

Gnaiger E, Steinlechner-Maran R, Mendez G, Eberl T, Margreiter R. (1995) Control of mitochondrial and cellular respiration by oxygen. J Bioenerg Biomembr.; 27: 367-72.

Hittelman KJ, Lindberg O, Cannon B. (1969) Oxidative phosphorylation and compartmentation of fatty acid metabolism in brown fat mitochondria. Eur J Biochem.; 11: $183-92$.

Houštěk J, Drahota, Z. (1975) Regulation of glycerol-3-phosphate oxidase of rat brown adipose tissue mitochondria by long chain free fatty acids. Mol Cell Biochem.; 7: 45-50.

Houštěk J, Cannon B, Lindberg O. (1975) Glycerol-3-phosphate shuttle and its function in intermediary metabolism of hamster brown adipose tissue. Eur J Biochem.; 54: 11-8.

Ishihara H, Nakazaki M, Kanegae Y, Inukai K, Asano T, Katagiri H, Jazaki Y, Saito I, Oka Y. (1996) Effect of mitochondrial and/or cytosolic glycerol 3-phosphate dehydrogenase overexpression on glucose-stimulated insulin secretion from MIN6 and HIT cells Diabetes.; 45: $1238-44$.

Lardy H, Partridge B, Kneer N, Wei Y. (1995) Ergosteroids: induction of thermogenic enzymes in liver of rats treated with steroids derived form dehydroepiandrosterone. Proc Natl Acad Sci U S A.; 92: 6617-9.

Lardy H, Su Ch-Y, Kneer N, Weilgus S. (1989) Dehydroepiandrosterone induces enzymes that permit thermogenesis and decrease metabolic effifiency. In: Hormones, 
Thermogenesis and Obesity. Lardy $\mathrm{H}$,

Stratman F, eds, pp 415-26. Elsevier.

Lenaz G. (2001) A critical appraisal of the mitochondrial coenzyme Q pool. FEBS Lett.; 509: 151-5.

Lowry OH, Rosebrough NJ, Farr AL, Randall LJ. (1951) Protein measurement with Folin phenol reagent. J Biol Chem.; 143: 265-75.

MacDonald MJ, Brown LJ. (1996) Calcium activation of mitochondrial glycerol phosphate dehydrogenase restudied. Arch Biochem Biophys.; 326: 79-84.

MacDonald MJ, Efendic S, Ostenson CG. (1996) Normalization by insulin treatment of low mitochondrial glycerol phosphate dehydrogenase and pyruvate carboxylase in pancreatic islets of the GK rat. Diabetes.; 45: $886-90$.

Nalecz MJ, Zborowski J, Famulski KS, Wojtczak L. (1980) Effect of phospholipid composition on the surface potential of liposomes and the activity of enzymes incorporated into liposomes. Eur J Biochem.; 112: 75-80.

Olivera AA, Meigs RA. (1975) Mitochondria from human term placenta. II. Characterization of respiratory pathways and coupling mechanisms. Biochim Biophys Acta.; 376: 436-45.

Rauchová H, Drahota Z. (1984) Inhibition of glycerol-3 phosphate oxidation by free fatty acids. Int J Biochem.; 16: 243-5.

Rauchová H, Battino M, Fato R, Lenaz G, Drahota Z. (1992) Coenzyme Q pool function in glycerol-3-phosphate oxidation in hamster brown adipose tissue mitochondria. $J$ Bioenerg Biomembr.; 24: 235-41.

Rauchová H, Beleznai Z, Drahota Z. (1993) Dual role of fatty acids regulation of mitochondrial
L-glycerol phosphate dehydrogenase. Biochem Mol Biol Int.; 30: 139-46.

Rauchová H, Kalous M, Drahota Z. (1993) The effect of phospholipase $A_{2}$ on mitochondrial glycerol-3-phosphate oxidation. Physiol Res.; 42: 319-22.

Rauchová H, Fato R, Drahota Z, Lenaz G. (1997) Steady-state kinetic of reduction of coenzyme Q analogs by glycerol-3-phosphate dehydrogenase in brown adipose tissue mitochondria. Arch Biochem Biophys.; 344: $235-41$.

Schagger H, Pfeiffer K. (2001) The ratio of oxidative phosphorylation complexes I-IV in bovine heart mitochondria and the composition of respiratory chain supercomplexes. $J$ Biol Chem.; 276: 37861-7.

Senner A, Lieselote H, Malaisse WJ. (1996) FAD-linked glycerophosphate dehydrogenase deficiency in pancreatic islets of mice with hereditary diabetes. FEBS Lett.; 316: 224-7.

Scholz TD, TenEyck CJ, Schulte BC. (2000) Thyroid hormone regulation of the NADH shuttles in liver and cardiac mitochondria. $J \mathrm{Mol}$ Cell Cardiol.; 32: 1-10.

Swierczynski J, Scislowski P, Alexandrowicz Z. (1976) High activity of glycerophosphate oxidation by human placenta mitochondria. Biochim Biophys Acta.; 429: 46-54.

Weitzel JM, Kutz S, Radtke Ch, Grott S, Seitz HJ. (2001) Hormonal regulation of multiple promotrs of the rat mitochondrial glycerol-3-phosphate dehydrogenase gene. Eur $J$ Biochem.; 268: 4095-103.

Wojtczak L, Nalecz M. (1979) Surface charge of biological membranes as a possible regulator of membrane-bound enzymes. Eur $J$ Biochem.; 94: 99-107. 